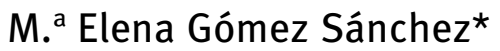

\title{
Candidatos, partidos políticos y electores: actividades de imagen en las cartas electorales españolas para las elecciones al Parlamento Europeo (2004-2019)
}

\section{Candidates, political parties and electors: Facework in Spanish electoral letters for the elections to the European Parliament (2004-2019)}

https://doi.org/10.1515/soprag-2021-0015

Publicado en línea noviembre 5, 2021

Resumen: Este trabajo, de carácter exploratorio, descriptivo e interpretativo, estudia las actividades de imagen presentes en un conjunto de cartas electorales enviadas por los principales partidos políticos españoles a los ciudadanos de ese país entre 2004 y 2019; concretamente, las cartas electorales relativas a las elecciones al Parlamento Europeo celebradas en 2004, 2009, 2014 y 2019. Las cartas electorales constituyen una parte del discurso político escrito (Anaya Revuelta, 2018) en las que el candidato a unas elecciones (en ocasiones, acompañado en la misma misiva, o en otra diferente -pero que forma parte del mismo envío-por otro texto del secretario general o el presidente de su partido) se dirige a los potenciales votantes con un discurso persuasivo, orientado a conseguir su voto. En este contexto, las actividades que se llevan a cabo son principalmente de autoimagen, si bien es posible encontrar también actividades de cortesía (hacia los lectores) y críticas hacia otros partidos políticos - $\mathrm{u}$ otros actores sociales-que se enmarcan en una descortesía muchas veces carente de identificación del sujeto concreto al que se dirige y que, en ese sentido, entendemos como despersonalizada. Este trabajo pone de manifiesto tales actividades (y, por ende, el modo en el que se construye la imagen de los candidatos), mediante el análisis y comparación de estas cartas, no solo de manera sincrónica (las cartas que se envían desde distintos partidos para

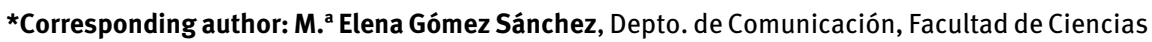
Sociales y de la Comunicación, Universidad Europea de Madrid Campus de Villaviciosa de Odón, C/ Tajo, s/n, Villaviciosa de Odón, Madrid, 28670, Spain, E-mail: elena.gomez@universidadeuropea.es

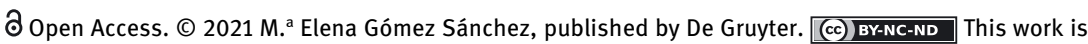
licensed under the Creative Commons Attribution-NonCommercial-NoDerivatives 4.0 International License. 
unas mismas elecciones) sino también, cuando es posible, de manera diacrónica (las cartas que un mismo partido envía a sus potenciales electores a lo largo del tiempo). Creemos que todavía no hay ningún trabajo que haya analizado este tipo de textos desde la perspectiva aquí planteada, por lo que consideramos que es un estudio que, además de original, puede abrir camino a otros investigadores que deseen realizar análisis similares o con los que establecer comparaciones.

Palabras clave: discurso político, cartas electorales, (des)cortesía, actividades de autoimagen

Abstract: This paper - of an exploratory, descriptive, and interpretative nature addresses facework in a corpus of electoral letters sent by the main Spanish political parties from 2004 to 2019 to the citizens. Specifically, research focuses on the electoral letters related to the elections to the European Parliament held in 2004, 2009, 2014 and 2019. Electoral letters are part of the written political discourse as texts in which the candidates to any given elections (sometimes signing alone, sometimes signing together with the President of their Parties, and sometimes along with another text from the President of their Parties sent in the same dispatch) address the potential voters with a persuasive discourse, pursuing to receive their votes. In this context, the candidates' facework is mostly self-oriented, although there are also politeness strategies addressed to the readers, and criticism towards other political parties or other social actors. Such criticism, framed in impoliteness, often avoids the specific identification of the subject to whom it is addressed, and, in this sense, it can be understood as a depersonalized impoliteness. This paper shows facework (and therefore, the way in which the image of candidates is created) by examining and comparing these letters, not just synchronically (letters sent by different parties regarding the same elections) but also, when possible, diachronically (letters sent by each party to their potential electors along the years).

Keywords: political discourse, electoral letters, (im)politeness, self-oriented facework

\section{Introducción}

Los discursos políticos de distinta índole constituyen un campo ampliamente estudiado (véase, como ejemplo reciente, la panorámica considerada en Narvaja de Arnoux, 2021); igualmente, se cuenta con múltiples análisis sobre actividades de imagen, cortesía y descortesía en el ámbito de la política (sirva como ejemplo la mención a numerosos estudios en el marco de las actividades del programa EDICE, 
de los cuales tan solo citaremos aquí los de Bolívar y Escudero, 2021; Hernández Flores y Gómez Sánchez, 2014; Kaul de Marlangeon y Cordisco, 2014; Kaul de Marlangeon, 2017; Ridao, 2009; entre otros muchos posibles). Asimismo, en los últimos años son frecuentes los trabajos dedicados a formas de comunicación política en redes sociales como Facebook o Twitter, e incluso centrados específicamente en los mensajes de campañas electorales en estos canales (cfr. Abejón y Mayoral, 2017; Abejón, Sastre, y Linares, 2012; Alcantara Plá y Ruiz Sánchez, 2018; Ballesteros y Gómez, 2020; López Meri, Marcos García, y Casero Ripollés, 2020; Marcos García, Alonso Muñoz, y López Meri, 2021; Sampietro y Valera, 2015; Zugasti y García, 2018). Sin embargo, son prácticamente inexistentes los análisis centrados en las cartas electorales como forma de comunicación política ${ }^{1}$. En este sentido, cabe señalar el trabajo de Anaya (2018) que, no obstante, cuenta con una orientación muy distinta a la nuestra, en tanto que esta investigadora se centra en un análisis secuencial y enunciativo, mientras que en este trabajo emplearemos la perspectiva de los análisis sobre (des)cortesía y negociación de la imagen.

Esta aproximación constituye un enfoque novedoso, pues no conocemos ningún trabajo en el que este análisis se haya aplicado al discurso presente en las cartas electorales, ni a cómo se presenta lingüísticamente la imagen de los emisores en este tipo de texto, o a las estrategias de cortesía y descortesía (en definitiva, de negociación de su imagen) que los emisores van a emplear para (intentar) lograr sus propósitos, aunque su interlocutor vaya a leer el texto en un momento diferente al que fue escrito (es decir, se trata de una comunicación en diferido). Desde esta perspectiva, en el epígrafe 2 aportaremos las bases teóricas sobre las que se sustentan los dos objetivos de esta investigación: caracterizar las actividades de cortesía, descortesía y autoimagen presentes en las cartas electorales que constituyen nuestro corpus y, a partir de ello, establecer el modo en que tales actividades contribuyen a configurar la imagen de los candidatos y los partidos. En el epígrafe 3 nos detendremos en algunas consideraciones sobre las cartas electorales -dentro de un marco más amplio, el del discurso político-y dedicaremos el epígrafe $4 \mathrm{al}$ análisis de los textos. Finalmente se ofrecen las oportunas conclusiones y se proponen otras posibles líneas de investigación.

1 No ha sido sencillo encontrar una definición concisa relativa a carta electoral. Así pues, agradezco al Dr. M. Á. Benedicto la siguiente formulación: "Documento escrito de propaganda electoral que utilizan los partidos para resumir su programa político o recalcar las ideas principales de su programa en busca del voto" (comunicación personal). 


\section{Marco teórico}

Este trabajo se aborda desde el prisma de la pragmática sociocultural, entendida como "un enfoque de estudio del uso del lenguaje [...] en el cual el/la analista incorpora 'explícitamente` a su aparato analítico el `contexto extralingüístico’ que justifica sus interpretaciones. Este tipo de contexto tiene que ver con el sistema sociocultural al cual los hablantes adhieren” (Bravo, 2020, p. 482). Desde la perspectiva de este paradigma teórico y para nuestros fines específicos, a partir de la noción de imagen social ( face, Goffman, 1967) emplearemos, en primer lugar, el concepto de actividades de imagen ( face-work; cfr. Goffman, 1967, p. 12) en tanto que acciones que una persona lleva a cabo para que su conducta sea coherente con su imagen propia ${ }^{2}$. Más concretamente, dentro de las posibles actividades de imagen (actividades de cortesía, descortesía y autoimagen) que un individuo puede llevar a cabo, nos interesan especialmente en este trabajo las actividades de autoimagen, entendidas como aquel "comportamiento comunicativo con una repercusión positiva o negativa sobre la imagen de uno mismo, es decir, sobre la imagen del hablante, quedando la del destinatario fuera de los efectos de este comportamiento" (Hernández Flores, 2006, p. 638). No obstante, recogemos también en los párrafos siguientes algunas reflexiones relacionadas tanto con la cortesía como con la descortesía, en tanto que actividades de imagen que también aparecen en los textos que analizaremos en el epígrafe 4 de este estudio.

Por lo que se refiere al concepto de cortesía, partimos de su conceptualización como modo de codificación lingüística de la interacción social (cfr. Bou Franch y Garcés Conejos, 2003; Garcés Conejos, 1995), y también de su definición como "una actividad comunicativa cuya finalidad propia es quedar bien con el otro y que responde a normas y a códigos sociales que se suponen en conocimiento de los hablantes (Bravo, 2005, p. 33). Además, en relación con la caracterización de la cortesía y sus efectos sobre la propia imagen, también nos interesa el enfoque de Hernández Flores (2004, p. 99) cuando señala que "el objetivo de la cortesía podría ser no solo satisfacer los deseos de imagen del otro [...] sino satisfacer tanto los deseos de imagen del otro como los de uno mismo”. Esta aproximación, a su vez, se enmarca en la idea de que

2 "By face-work I mean to designate the actions taken by a person to make whatever he is doing consistent with face" (Goffman, 1967, p. 12). Para este autor, la imagen social se define como el valor social positivo que alguien reclama para sí mismo a partir de la postura que los demás suponen que ha tomado en un contacto determinado. Por otra parte, hemos de referirnos también aquí a los conceptos de autonomía y afiliación como componentes de la imagen. Si bien dejamos su definición para momentos posteriores de este trabajo, cabe apuntar ya aquí que se trata de categorías vacías de contenido sociocultural, que se llenan con contenidos propios de cada contexto específico (cfr. Bravo, 2003). 
"en una interacción comunicativa los participantes tienen unos deseos de imagen, los cuales se caracterizarían de acuerdo con aspectos socioculturales de su propia comunidad" (Hernández Flores, 2004, p. 99), y se vincula con "la revalorización del contexto del usuario [...] considerado este último como miembro de un grupo social que usa la lengua en estudio de modo habitual y que comparte con los demás miembros del mismo grupo, al menos, el 'reconocimiento' de las pautas socioculturales que rigen la comunicación” (Bravo, 2020, p. 482).

Por otra parte, para lo referido al concepto de descortesía se parte de la definición de Lakoff (1989, p. 103) en tanto que estas actividades suponen actos que implican una confrontación "intencional y negativa”, pero también nos serviremos de la aproximación de Culpeper, Bousfield, y Wichmann (2003, p. 1546) en tanto que se trata del uso de estrategias que atacan "la imagen social, y por las cuales se crea conflicto y desarmonía”. Asimismo, nos interesa la consideración de que el comportamiento descortés "menosprecia, desatiende, desprotege, desfavorece, se opone a, ofende, rebaja o perjudica (aspectos de) la imagen social del otro [...]" (Lancheros, 2020, p. 42) y, en definitiva, el hecho de que produce un efecto $^{3}$ negativo en la imagen del destinatario de esa descortesía, concebida, en resumen, como "una actividad comunicativa a la que se le atribuye la finalidad de dañar la imagen del otro y que responde a códigos sociales supuestamente compartidos por los hablantes” (Bernal, 2007, p. 169; cursivas de la autora).

No perdemos tampoco de vista el hecho de que el objeto de nuestro estudio se enmarca en el discurso político, en el cual las muestras de descortesía estratégica (Kienpointner, 1997), uno de los tipos posibles de descortesía motivada, aparecen con frecuencia y pueden considerarse un ejemplo de descortesía normativa "en el sentido de que es un comportamiento esperado” (Bernal, 2007, p. 172). Relacionado con ello, no puede tampoco obviarse la presencia de tres tipos de destinatarios en el discurso político (y en las cartas que aquí se analizan): el contradestinatario (el adversario), el prodestinatario (aquellos que comparten el espacio ideológico del enunciador) y el paradestinatario (aquellos a quienes se pretende convencer; a estos "va dirigido todo lo que en el discurso político es del orden de la persuasión” [Verón, 1987, p. 17]).

Además, aunque no sea el enfoque de análisis primordial para este trabajo, debe también tenerse en cuenta que en la comunicación política los marcos o frames seleccionados por cada uno de los candidatos juegan un papel relevante desde el mismo momento de la concepción del discurso. De este modo, consideraremos también, cuando ello sea preciso, la definición de frame aportada por Igartua, Muñoz y Cheng (2005, p. 158), para quienes este concepto "remite al

3 El concepto de efecto social se refiere a las consecuencias que tiene una actividad comunicativa sobre el clima socioemocional que se produce en la interacción (cfr. Bravo, 2002, 2005; Hernández Flores, 2013). 
ángulo, enfoque, perspectiva o tratamiento de una información que se manifiesta en la elección, énfasis o importancia atribuida a diferentes elementos y, en particular, en la forma cómo covarían dichos elementos más o menos enfatizados en un texto", pues creemos que resulta relevante para la configuración de la imagen de los candidatos y los partidos a los que representan.

Finalmente, tampoco puede dejarse de lado (y, de hecho, se ha revelado como un aspecto importante en esta investigación) la presencia en estas cartas electorales de estrategias relacionadas con la cortesía y la descortesía que encuentran su correlato en actividades reflejadas en el cuadrado ideológico de T. A. Van Dijk (con la contraposición entre nosotros y ellos y las correspondientes acciones para la maximización o minimización de los aspectos positivos y negativos de cada uno de esos grupos; cfr. Van Dijk, 1999, p 333; Van Dijk, Ting-Toomey, Smitherman y Troutman, 2000, p. 250 $)^{4}$, pues se constituyen en procedimientos habituales para la configuración de la imagen de los candidatos y los partidos a los que representan.

\section{Las cartas electorales como género discursivo. Corpus empleado}

Las cartas electorales constituyen un género discursivo (entendido éste como "un tipo de discurso, o más ampliamente de actividad verbal o evento comunicativo"; Van Dijk, 2012, p. 221) que, además, se entienden como textos políticos por su propia naturaleza, toda vez que "se considera como «discurso político» aquel que surge en el marco de actividades sociales destinadas a alcanzar, gestionar o defender el poder, que se inscribe en géneros asociados tradicionalmente con aquellas, sostenido por locutores legitimados institucionalmente y que responde a

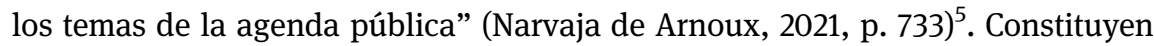
igualmente un ejemplo de texto persuasivo, caracterizada la persuasión como "una actividad consciente que se realiza de manera intencionada con el fin de inducir a un auditorio a pensar o actuar de una determinada manera, a través de estrategias que cuentan como base la palabra junto con otras técnicas [...]" (De Santiago Guervós, 2020, p. 429). Su objetivo es claro: lograr la confianza de los electores para obtener su voto frente a las opciones que puedan ofrecer otros

4 Cabe también mencionar aquí a Charaudeau (2004), quien señala que en el discurso político, cuando el político se dirige al ciudadano, el adversario ocupa el lugar de un tercero.

5 "Para las entidades políticas, el envío de propaganda electoral [...] es una de las mejores formas para llegar individualmente a cada uno de los electores, a los que se remite un sobre con las papeletas electorales, los sobres electorales y una carta firmada por el líder o cabeza de la lista”. (http://guiasjuridicas.wolterskluwer.es, entrada "Propaganda electoral”). 
candidatos; es decir, no son textos orientados prioritariamente a la información, sino a la movilización; en este sentido, como señala Anaya Revuelta (2018, p. 71), tienen "una fuerte intención perlocutiva”. Por otra parte, son textos que -en tanto que escritos- desde el punto de vista de su distancia concepcional (cfr. Koch y Oesterreicher, 1990; Oesterreicher, 1996) se entenderían como “distantes” en tanto que se constituyen en "un discurso autónomo, desvinculado de su autor, donde la reducción del contexto inmediato y la separación del presente es manifiesta" (Pons, 2021, p. 289); sin embargo, también presentarían rasgos de "inmediatez", dado que en ellos se vuelcan elementos de proximidad temática y emocional entre el texto y quien lo produce (cfr. Pons, 2021, p. 289). Así, habría un desplazamiento dentro del continuo desde la distancia hacia la inmediatez con el fin de aproximarse a sus destinatarios, en el marco de esa finalidad persuasiva y estrechamente relacionada con la construcción de la imagen de los candidatos.

Además, debe considerarse que, aunque en el momento de enviar la carta electoral y en el momento de leerla emisor e interlocutor (o, dicho en un sentido más amplio, el alocutor ciudadanía) no se encuentran físicamente frente a frente (al igual que ocurriría habitualmente con cualquier otro ejemplo de género epistolar), se establece un cierto pacto sobre esa comunicación, como si se generase de manera inmediata, cercana; asimilándola, en cierto modo, a una comunicación cara a cara (y el empleo de fotografías de los candidatos en las cartas electorales no es algo ajeno a ello). Es decir, el político "no olvida que es precisamente a los ciudadanos a quienes se dirige y que, por tanto, debe aparecer ante ellos con la imagen pública que considere más adecuada" (Gómez Sánchez, 2008, p. 22); de hecho, ese es su principal propósito. Ahora bien, aunque pueda establecerse ese pacto, la comunicación de las cartas electorales no deja de producirse de manera unidireccional: el candidato habla al posible elector, pero la reacción por parte del interlocutor, el ciudadano, se producirá con posterioridad, al otorgarle o no su voto. Así pues, desde esta perspectiva, "la ausencia «física» del alocutor/interlocutor «ciudadano» [...] no implica la inexistencia de estrategias de cortesía y descortesía dirigidas a esos destinatarios «no visibles», sino que [...] tales estrategias aparecen integradas dentro de las actividades de autoimagen que [los políticos] llevan a cabo, y que contribuyen a configurar su imagen pública. Dicho de otro modo, lo cortés y lo descortés se hace presente [...] al hablar de las medidas propuestas o desarrolladas por su partido, de sus apoyos y oponentes, de su percepción de la ciudadanía, etc.” (Gómez Sánchez, 2008, p. 22).

Nuestro corpus de análisis -un total de dieciocho textos-está formado por las cartas electorales enviadas por los principales partidos políticos a los ciudadanos españoles para las elecciones europeas celebradas entre 2004 y 2019 (2004, 2009, 2014 y 2019). En la tabla siguiente se indican esos partidos y las personas que actuaron como candidatos principales para cada uno de ellos en los distintos comicios (se incluyen uno o dos apellidos en función de cómo aparecieran en las 
cartas). El orden en el que se presentan los partidos en las columnas responde al hecho de que ya se presentaran a las elecciones en los años indicados en la primera columna o todavía no y, en caso de presentarse por primera vez en un mismo momento, se sigue un orden alfabético ${ }^{6}$.

Tabla 1: Cartas electorales consideradas en el estudio (2004-2019).

\begin{tabular}{|c|c|c|c|c|c|c|c|}
\hline & PP & PSOE & IU & Ciudadanos & UPyD & Podemos & Vox \\
\hline $\begin{array}{l}2004 \text { (Partido } \\
\text { en el } \\
\text { Gobierno en } \\
\text { ese } \\
\text { momento: } \\
\text { PSOE) }\end{array}$ & $\begin{array}{l}\text { Jaime } \\
\text { Mayor } \\
\text { Oreja }\end{array}$ & $\begin{array}{l}\text { Josep } \\
\text { Borrell }\end{array}$ & $\begin{array}{l}\text { Carta no } \\
\text { disponible }^{7}\end{array}$ & $\begin{array}{l}\text { Formación } \\
\text { inexistente } \\
\text { en aquel } \\
\text { momento }\end{array}$ & $\begin{array}{l}\text { Formación } \\
\text { inexistente } \\
\text { en aquel } \\
\text { momento }\end{array}$ & $\begin{array}{l}\text { Formación } \\
\text { inexistente } \\
\text { en aquel } \\
\text { momento }\end{array}$ & $\begin{array}{l}\text { Formación } \\
\text { inexistente } \\
\text { en aquel } \\
\text { momento }\end{array}$ \\
\hline $\begin{array}{l}2009 \text { (Partido } \\
\text { en el } \\
\text { Gobierno en } \\
\text { ese } \\
\text { momento: } \\
\text { PSOE) }\end{array}$ & $\begin{array}{l}\text { Jaime } \\
\text { Mayor } \\
\text { Oreja }\end{array}$ & $\begin{array}{l}\text { Juan Fer- } \\
\text { nando } \\
\text { López } \\
\text { Aguilar }\end{array}$ & $\begin{array}{l}\text { Carta no } \\
\text { disponible }\end{array}$ & $\begin{array}{l}\text { Se presentó } \\
\text { en coalición } \\
\text { a las eleccio- } \\
\text { nes - carta } \\
\text { no } \\
\text { disponible }\end{array}$ & $\begin{array}{l}\text { Carta no } \\
\text { disponible }\end{array}$ & $\begin{array}{l}\text { Formación } \\
\text { inexistente } \\
\text { en aquel } \\
\text { momento }\end{array}$ & $\begin{array}{l}\text { Formación } \\
\text { inexistente } \\
\text { en aquel } \\
\text { momento }\end{array}$ \\
\hline $\begin{array}{l}2014 \text { (Partido } \\
\text { en el } \\
\text { Gobierno en } \\
\text { ese } \\
\text { momento: PP) }\end{array}$ & $\begin{array}{l}\text { Miguel } \\
\text { Arias } \\
\text { Cañete }\end{array}$ & $\begin{array}{l}\text { Elena } \\
\text { Valenciano }\end{array}$ & Willy Meyer & Javier Nart & $\begin{array}{l}\text { Francisco } \\
\text { Sosa } \\
\text { Wagner }\end{array}$ & $\begin{array}{l}\text { Pablo } \\
\text { Iglesias }\end{array}$ & $\begin{array}{l}\text { Alejo Vidal- } \\
\text { Quadras }\end{array}$ \\
\hline $\begin{array}{l}2019 \text { (Partido } \\
\text { en el } \\
\text { Gobierno en } \\
\text { ese } \\
\text { momento: } \\
\text { PSOE) }\end{array}$ & $\begin{array}{l}\text { Dolors } \\
\text { Montserrat }\end{array}$ & $\begin{array}{l}\text { Josep } \\
\text { Borrell }\end{array}$ & $\begin{array}{l}\text { [Coalición } \\
\text { electoral } \\
\text { con Unidas } \\
\text { Podemos] }\end{array}$ & $\begin{array}{l}\text { Luis } \\
\text { Garicano }\end{array}$ & $\begin{array}{l}\text { La forma- } \\
\text { ción no se } \\
\text { presentó a } \\
\text { estas } \\
\text { elecciones }\end{array}$ & $\begin{array}{l}\text { Firmada } \\
\text { como } \\
\text { Unidas } \\
\text { Podemos } \\
\text { Cambiar } \\
\text { Europa } \\
\text { [coalición } \\
\text { electoral } \\
\text { con IU] }\end{array}$ & $\begin{array}{l}\text { Carta no } \\
\text { disponible }\end{array}$ \\
\hline
\end{tabular}

6 Puede darse la circunstancia de que una carta esté firmada, no solo por el cabeza de lista, sino también por el secretario general de su partido, como ocurre en las cartas enviadas por el Partido Socialista Obrero Español (en adelante, PSOE) en 2004 y 2009 y por el Partido Popular (en adelante, PP) en 2004, o que la carta del cabeza de lista sea acompañada por otra carta del presidente del partido (es el caso del PP en 2009, 2014 y 2019); en esos casos también hemos analizado estas cartas.

7 Pese a las búsquedas realizadas en archivos de distinta índole y consultas a las propias formaciones políticas, no ha sido posible localizar determinadas cartas electorales y así lo indicamos en esta tabla (sí pueden encontrarse programas electorales, pero no se han tenido en cuenta en tanto que constituyen un tipo de discurso diferente del que aquí estudiamos). 


\section{Análisis del corpus}

En esta sección mostramos las actividades de cortesía, descortesía y autoimagen presentes en las cartas electorales consideradas ${ }^{8}$. Por razones de espacio los ejemplos no pueden tener ánimo de exhaustividad, así que se seleccionan textos representativos para cada una de estas categorías, teniendo en cuenta los objetivos de este trabajo.

\subsection{Actividades de cortesía: saludos y despedidas, el halago a los (e)lectores y la búsqueda de la proximidad}

En primer lugar, y en la medida en que tanto saludar como despedirse son acciones que se relacionan estrechamente con la cortesía, nos referiremos al modo en que estos actos de habla se hacen presentes mediante las fórmulas rituales de saludo (encabezamiento) y despedida en las cartas electorales consideradas, así como a la fórmula de tratamiento (tú/usted) con la que se dirigen al lector. Así, el PSOE emplea la fórmula "usted" (en principio, más respetuosa) en tres (2004, 2009 y 2014) de las cuatro cartas, si bien cambia al tuteo en la de 2019. El PP, por su parte, es más proclive al uso del tuteo (solo emplea el "usted" en la carta de 2009). En relación con ello, podría pensarse en una mayor muestra de cortesía formal por parte del PSOE (excepto en 2019, cuando esa cortesía formal cedería terreno en pro de un mayor acercamiento al lector, que de hecho también supondría una mayor cortesía en tanto que la carta se personaliza o individualiza con el nombre de su destinatario -por ejemplo, “Estimada Carmen”-, aunque obviamente sea un procedimiento automático) y justo en el empleo de la estrategia contraria por parte del PP (la búsqueda de mayor cercanía como tónica habitual mediante el uso del tuteo). En cuanto al léxico empleado, tanto PSOE como PP como Vox utilizan fórmulas como "Estimado/a amigo/a" y "Querido/a amigo/a” (que, si bien ritualizadas y genéricas, muestran cierto afecto y cercanía), mientras que en las elecciones de 2014, UPyD emplea un "respetado/a ciudadano/a" que remite a una cortesía más "protocolaria” (por las connotaciones asociadas a "respeto") y Podemos opta por un "ciudadana/ciudadano" que precisamente resalta el valor político del término y supone más una apelación (o "invocación”) que una fórmula de saludo al uso. En las elecciones de 2019, la coalición Unidas Podemos Cambiar Europa antepone un "estimada, estimado" a la denominación de "ciudadana,

8 Tanto en las tablas como en el análisis respetamos la grafía (mayúsculas/minúsculas) y tipografía (redonda/negritas) utilizadas en las cartas electorales que forman nuestro corpus. 
ciudadano" con la que se dirige a los lectores, lo que supone un tratamiento menos brusco -y, por ende, más cortés- que el empleado en 2014.

Por lo que se refiere a las fórmulas de despedida (cuando aparecen, lo que no siempre ocurre), es mayoritario el uso de "un cordial saludo" para el destinatario (en ocasiones extensible "a los suyos", como es en el caso de las cartas del PSOE de 2004 y 2014, lo que aumenta la cortesía empleada), así como el mostrarse agradecido (lo que aparece en las cartas de PP y PSOE de 2009 y en las del PP de 2014; en este caso, se intensifica -en la de M. Arias-con un “muchísimas gracias”). Solo la carta de 2019 enviada por el presidente del PP aumenta el grado de cercanía con los lectores al despedirse con "un fuerte abrazo"; en cuanto al resto de los partidos, omiten estas fórmulas de cortesía y suelen concluir sus textos directamente con la "llamada a la acción" (esto es, la solicitud de voto).

Avanzando en el análisis, y más allá de lo que estas fórmulas ritualizadas suponen, cabe señalar que las actividades de cortesía hacia los (e)lectores aparecen muy frecuentemente en los primeros párrafos de las cartas que conforman nuestro corpus de estudio. Así, nuestro análisis revela la voluntad de halagar y el deseo de potenciar la cercanía con los (e)lectores como estrategias corteses especialmente significativas. En este sentido, uno de los recursos que se ha revelado más productivo es el empleo de la primera persona de plural (nosotros) como forma de eliminar la posible distancia que pueda haber entre emisores y destinatarios (en la línea de lo señalado por Lakoff (1973) respecto a buscar puntos de encuentro entre los interlocutores), y dentro también de un comportamiento esperable en una “cultura de acercamiento" (Briz, 2004), como la española, al quedar englobados en un mismo conjunto:

1. "El día 13 de junio, todos los ciudadanos de la Unión europea elegiremos a nuestro Parlamento común, el Parlamento Europeo. Y los españoles votaremos a quienes nos van a representar en Europa durante los próximos años. Son unas elecciones de extraordinaria importancia para todos”. (Carta de 2004 del PSOE, firmada por José Luis Rodríguez Zapatero y por José Borrell)

2. “A los españoles nos gusta y nos conviene estar en Europa y ser parte relevante en sus decisiones”. (Carta de 2004 del PSOE, firmada por José Luis Rodríguez Zapatero y por José Borrell)

En el segundo ejemplo, la imagen que se ofrece a los electores ya no es solo de proximidad o de inclusión en el endogrupo, sino que se va un paso más allá: se busca la complicidad con el destinatario, de quien se considera que comparte el mismo punto de vista ("nos gusta"), a la vez que se apela a su imagen racional ("nos conviene"), con las connotaciones positivas que ello tiene para su imagen, 
pues queda reflejado como una persona inteligente y que aplica esa inteligencia a su toma de decisiones (además de transmitir la imagen de que los ciudadanos tienen poder de decisión, lo que también constituye un halago). Se potencia, en definitiva, la afiliación, categoría que, desde el punto de vista de la imagen, reúne “aquellos comportamientos en los cuáles se refleja cómo una persona desea verse y ser vista por los demás en cuanto a aquellas características que la identifican con el grupo" (Bravo, 2002, p. 106).

También se aprecian estas estrategias para el acercamiento al lector en las cartas enviadas por el PP en 2004 y 2009; en esta última, la complicidad se acentúa hasta el punto de presuponer que el lector comparte su punto de vista:

3. "Una vez más nos llega la ocasión de ejercer nuestro derecho democrático" [...]. Una cita de gran trascendencia, a la que no podemos faltar" (Carta de 2004 del PP, firmada por Mariano Rajoy y por Jaime Mayor Oreja)

4. "No voy a insistir en lo que usted sabe tan bien como yo. Tenemos problemas muy graves a los que este Gobierno no está dando las soluciones adecuadas [...] Tenemos que poner este país a trabajar, con un modelo nuevo, más competitivo y sostenible”. (Cartas de 2009 del Partido Popular, firmadas por Mariano Rajoy y por Jaime Mayor Oreja)

El empleo de la primera persona del plural en el ejemplo anterior se relaciona también con una idea de acción en la que se actualiza (pues ya apareció en la carta enviada por este partido en 2004) la noción de competitividad, a la que se suma la de sostenibilidad. ${ }^{9}$

5. “Los españoles y los europeos hemos demostrado que somos más fuertes juntos. Recuperemos la esperanza de compartir un proyecto común [...] No queremos que nos dividan ni en bandos ni en tribus: somos ciudadanos libres e iguales. Debemos trabajar unidos para reformar aquello que no funciona [...]” (Carta de Ciudadanos de 2014, sin firma expresa)

9 Ello puede relacionarse con la observación de Cussó and Gobin (2008) al referirse al discurso político experto, presentado como un discurso "en el que las cuestiones políticas son transformadas en cuestiones técnicas, racionales que conforman un «sentido común» general adoptado acríticamente. Se caracteriza por la insistencia en objetivos generales que dejan pocas posibilidades de refutación" (Narvaja de Arnoux, 2021, p. 743). Cabe señalar, en cualquier caso, que no es algo exclusivo de esta carta (ni de esta formación política), pues pueden apreciarse ejemplos similares en cartas de partidos muy alejados ideológicamente entre sí. Es posible recordar también aquí la reflexión de Charaudeau (2021, pp. 103-104): "El discurso político está lleno de procedimientos [...] con la esperanza de un impacto en el público. Utilización de palabras que, nacidas en cierto contexto, se desprendieron de éste y son reutilizadas de manera absoluta, sin que ya se sepa quién las utilizó, a qué actores atañen, ni a propósito de qué fueron utilizadas [...]”. 
6. "No hace falta que te cuente lo que está ocurriendo en nuestro país” (Carta de 2014 de Podemos, firmada por Pablo Iglesias)

En el ejemplo de Ciudadanos se hace referencia explícita a "proyecto común", mientras que en la carta electoral de Podemos de 2014 se apela igualmente a la complicidad con el lector, con un recurso prácticamente igual al empleado por Rajoy en 2009. También se apela a la complicidad con el lector desde la primera línea de la carta enviada por Izquierda Unida en 2014:

7. "Sabemos que la mayoría estamos pagando injustamente la crisis" (Carta de 2014 de Izquierda unida, sin firma expresa)

Sin embargo, ese nosotros no siempre es inclusivo; de hecho, en las actividades de autoimagen que los partidos políticos llevan a cabo (como se detallará en la sección correspondiente), es mucho más frecuente que la primera persona de plural se circunscriba exclusivamente a la formación de que se trate. Así ocurre en el siguiente ejemplo (que incluimos aquí solo a título ilustrativo), en el que el empleo de las metáforas establece una noción de actividad -tanto mecánica como humana-, que connota impulso y recalca la idea de fortaleza en torno a la cual se construye la imagen del PSOE en esta carta (como analizaremos más adelante).

8. "Nosotros creemos en el proyecto de una Europa unida y fuerte [...]. Y queremos que España esté en el motor y en el corazón de Europa”. (Carta de 2004 del PSOE, firmada por José Luis Rodríguez Zapatero y por José Borrell)

Ahora bien, también es muy frecuente que ese plural no inclusivo abra paso nuevamente, en la llamada a la acción por parte de los posibles votantes, al plural englobador (conjugado con apelaciones directas, individualizadas, para las que se emplea tanto el tú como el usted), para potenciar de nuevo la cercanía entre emisores y receptores:

9. "Ahora el partido entre el pasado y el futuro se juega en Europa. Está usted convocado, todos lo estamos. Por todos nosotros y por nuestros hijos, que vivirán en la Europa que ahora construyamos. Por eso le pedimos que el 7 de junio acuda a votar y apoye con su voto al Partido Socialista, a los socialistas españoles y europeos”. (Carta de 2009 del PSOE, firmada por José Luis Rodríguez Zapatero y Juan Fernando López Aguilar)

10. Quedan pocos días para el 25 de mayo, cuéntales a tus amigos y familiares que juntos podemos. Los ciudadanos de a pie vamos a dar una sorpresa y una lección: la democracia es el poder de la gente. ¡Claro que Podemos! (Carta de 2014 de Podemos, firmada por Pablo Iglesias) 
11. "Hagamos historia juntos, vote a VOX" (Carta de 2014 de Vox, firmada por Alejo Vidal-Quadras)

También se encuentran en las cartas otras actividades de cortesía -como invitaciones y agradecimientos- dirigidos- a los lectores ${ }^{10}$. En estos casos, el reconocimiento de la imagen del destinatario suele estar individualizado (tanto si se emplea el tuteo como si se trata de usted):

12. "El próximo 7 de junio estamos llamados a elegir a nuestros representantes en el Parlamento Europeo. Quiero invitarle a que vote y a que lo haga por la lista del PP que encabeza Jaime Mayor Oreja”. (Cartas de $2009 \mathrm{del}$ $P P$, firmadas por Mariano Rajoy y por Jaime Mayor Oreja)

13. “Antes de nada quiero aprovechar esta oportunidad para agradecerte personalmente todos los esfuerzos que estás realizando” (Cartas de 2014 del PP, firmadas por Mariano Rajoy y por Miguel Arias Cañete)

En esa misma carta, posteriormente, Rajoy se dirige de nuevo de forma directa a sus posibles lectores. En estas frases hay una actividad de cortesía negativa, pues de una parte se trasluce cierta "superioridad", pero simultáneamente el emisor evita imponerse a la imagen de sus lectores ${ }^{11}$.

14. “Como sabrás, el próximo 25 de mayo todos los españoles tenemos una importante cita [...]. Quizá pienses que en estas elecciones no te juegas nada o que son un mero trámite. Permíteme decirte que nada más lejos de la realidad. En estas elecciones nos jugamos mucho”. (Cartas de 2014 del PP, firmadas por Mariano Rajoy y por Miguel Arias Cañete)

Ya en el párrafo final de la carta, se repite la estrategia de "no imposición":

15. "Por todo ello permíteme que aproveche estas líneas para pedir tu voto para el próximo 25 de mayo" (Cartas de 2014 del PP, firmadas por Mariano Rajoy y por Miguel Arias Cañete)

También se aprecia esa individualización en las cartas enviadas por el PSOE en 2014 y 2019:

10 También en la propia petición de voto -que normalmente se encuentra al final de cada cartahay muestras de cortesía; sin embargo, dado que en esas peticiones aparecen también frecuentemente actividades de autoimagen, tan solo hemos incluido aquí algunos ejemplos. Las trataremos con mayor profundidad en la sección dedicada a la construcción de la autoimagen por parte de los candidatos y los partidos.

11 Como Charaudeau señala (2021: 140), es frecuente que en el ethos de identificación, y con el objetivo de llegar al mayor número posible de personas, se conjuguen imágenes de modestia con imágenes de poder. 
16. "Como candidata del Partido Socialista, le pido que vaya a votar el 25 de mayo, y ayude con su voto a salvar la Europa unida que queremos, a defender el interés de España y a que prevalezcan los valores progresistas. Le pido que vote socialista”. (Carta de 2014 del PSOE, firmada por Elena Valenciano)

17. Europa es un proyecto que no puede detenerse ni volver atrás. Y tienes la oportunidad de impulsarlo con tu voto en las elecciones al Parlamento Europeo (Carta de 2019 del PSOE, firmada por Josep Borrell y Pedro Sánchez)

Junto a ello, cabe señalar que en la carta firmada por Elena Valenciano la petición de voto (la llamada a la acción) se plantea desde la humildad (en tanto que petición que puede ser atendida o no), pero combinada con términos ("salvar”, “defender") que indican valor, determinación (y suponen actividades de autoimagen, en tanto que se establece una estrecha vinculación entre esas acciones, la candidata y el partido que representa), mientras que la carta de 2019 opta por una estrategia de cortesía hacia el receptor, al destacar su "capacidad de acción”.

\subsection{Actividades de descortesía: la oposición nosotros/ellos, el ataque verbal y la descortesía despersonalizada}

Si bien la imagen que construyen de sí mismos los candidatos se cimenta en las actividades -tanto corteses como descorteses- que muestran las cartas, y no siempre resulta posible -como se ha apuntado previamente- establecer delimitaciones nítidas entre esas actividades de (des)cortesía y las de autoimagen (pues es muy frecuente que tanto una actividad cortés como descortés repercuta, de manera intencionada, en la imagen que el partido o el candidato quiera ofrecer de sí mismo) ${ }^{12}$, creemos conveniente destacar en este apartado algunas de las actividades de descortesía más significativas que aparecen en el corpus ${ }^{13}$. Como punto

12 Cabe relacionar esta circunstancia con la observación de Hernández Flores (2013, p. 183) en cuanto a la interconexión entre la imagen propia y la ajena, interconexión que "las sitúa, no en espacios separados e independientes entre sí, sino dentro de un mismo espacio donde permanecen unidas por una línea imaginaria que denomino continuo social. De esta forma, dado que la imagen de una persona se configura en relación con la de otras cuando entran en contacto comunicativo, el efecto social de la actividad comunicativa realizada nunca recae exclusivamente sobre la imagen de una de ellas, sino que, en virtud del continuo social, en un mayor o menor grado, también afecta a la de los demás, incluida la del propio hablante”.

13 "Las actividades potencialmente amenazantes pueden ir dirigidas a los diferentes aspectos de la imagen de la persona (de rol, individual, grupal en el caso de que ataña a miembros de su familia, a sus amigos, compañeros de trabajo, etc.) y van en su perjuicio de alguna manera" 
de partida, coincidimos aquí con Bolívar al hablar de "descortesía política intencionada", en tanto que esta presenta "fines estratégicos tales como cohesionar a los seguidores y polarizar entre amigos y `enemigos`” (Bolívar y Escudero, 2021, p. 6). El primer ejemplo que consideramos es de la carta enviada por el PSOE en 2004, en la que se aprecia un ataque directo -en forma de acusaciones-hacia el exogrupo, constituido por el principal partido competidor del PSOE en ese momento en la política española (aunque no aparezca caracterizado como ellos -el pronombre más empleado en el cuadrado ideológico de Van Dijk-sino como él). Además, esas acusaciones servirán para dar pie a una estrategia de autoimagen, como se detallará más adelante:

18. “El PP no cree en ese proyecto. Por eso su gobierno puso obstáculos al avance de la unidad europea, separó a España de los países que más pesan en Europa y contribuyó a dividir y debilitar a la Unión Europea en cuestiones decisivas como la guerra de Irak". (Carta de 2004 del PSOE, firmada por José Luis Rodríguez Zapatero y por José Borrell)

Ese mismo tipo de actividad descortés, una acusación -en este caso de ineficacia-, se aprecia en un ejemplo que ya ha sido considerado con anterioridad, perteneciente a la carta del PP de 2009 (y también dará pie, poco después, a una actividad de autoimagen, que recogeremos en la sección correspondiente):

19. "No voy a insistir en lo que usted sabe tan bien como yo. Tenemos problemas muy graves a los que este Gobierno no está dando las soluciones adecuadas [...] Tenemos que poner este país a trabajar, con un modelo nuevo, más competitivo y sostenible”. (Cartas de $2009 \mathrm{del}$ Partido Popular, firmadas por Mariano Rajoy y por Jaime Mayor Oreja)

Poco después, en esa misma carta de 2009 del PP, hay otra muestra de descortesía hacia el PSOE; sin embargo, no se le menciona explícitamente, sino que la capacidad de interpretación cotextual y contextual de que disponga el lector (la referencia temporal que se incluye, y el hecho de que el PSOE fuese el partido en el Gobierno en esos años en España), será lo que permita -o no- comprenderlo:

20. "No se construye Europa renunciando a defender nuestros intereses, como se ha hecho en estos años, sino haciéndolos valer”. (Cartas de 2009 del Partido Popular, firmadas por Mariano Rajoy y por Jaime Mayor Oreja)

(Bernal, 2007, p. 174). En nuestro corpus estas actividades se dirigen, fundamentalmente, al rol desempeñado por los adversarios políticos o, en ocasiones, al rol desempeñado por otros agentes sociales, como se mostrará en las páginas siguientes. 
Se trata de una descortesía sin mención explícita del referente al que se dirige (y, en este sentido, podríamos calificarla de matizada ${ }^{14}$ o, más propiamente, de despersonalizada por la ausencia de una figura claramente identificada a la que vaya dirigida); antes bien, para su comprensión se requiere un esfuerzo por parte de los lectores. Esta ausencia, a su vez, permite salvaguardar mejor la imagen del emisor, pues resultará más difícil que reciba un contraataque que si el ataque verbal se hubiera dirigido directamente a alguien, de modo inequívoco, y ese "alguien" quisiera defenderse (cfr. Gómez Sánchez, 2006).

En la carta enviada por el PSOE en 2009, en lugar de referirse directamente al Partido Popular (como sí ocurría en 2004), se obvia esa referencia y, en cambio, se polariza la denominación empleada para referirse a sus adversarios políticos al recurrir al sintagma "la derecha", al que se contrapone la referencia a "los socialistas españoles”:

21. "Le pondremos un ejemplo: hace unos meses, la derecha pretendió implantar en toda Europa la jornada laboral de 65 horas semanales. Los socialistas españoles nos enfrentamos a ello y conseguimos frenarlo. Si la derecha hubiera tenido la mayoría, hoy los derechos sociales en Europa habrían retrocedido varias décadas”. (Carta de 2009 del PSOE, firmada por José Luis Rodríguez Zapatero y Juan Fernando López Aguilar)

Es decir, se establece una polarización entre ellos y nosotros, o exogrupo y endogrupo, característica del discurso ideológico (cfr. Van Dijk, 1999), que se acentúa por la repetición del término "derecha", así como por el uso del verbo "enfrentarse" (actitud que suele asociarse a ideas como valentía, coraje o peligro) y por la implicatura de que el éxito se logró no sin dificultad ("conseguimos frenarlo"), lo que repercute también en la construcción de su propia imagen. Esta polarización se repite a continuación, vinculando ya directamente al PP con "la derecha europea":

22. "No es verdad, como pretenden el PP y la derecha europea, que para que la economía se recupere sea necesario facilitar los despidos, bajar los salarios y las pensiones, desproteger a los desempleados y debilitar la educación pública y la sanidad”. (Carta de 2009 del PSOE, firmada por José Luis Rodríguez Zapatero y Juan Fernando López Aguilar)

14 Si bien Pérez Vicente (2016, pp. 12-13) hace referencia a una “descortesía más matizada” (en el caso español) en su análisis contrastivo español-italiano de la descortesía verbal en televisión, el matiz que aportamos aquí es diferente, pues esta autora se refiere en su trabajo al hecho de estar esa descortesía "apoyada en la retórica y no en la crítica directa, buscando efectos de comicidad que no descalifiquen (o no tanto) a la persona”, mientras que nuestros ejemplos muestran la ausencia de identificación explícita de a quién (o quiénes) se dirige la actividad descortés (acusación, descalificación, etc.). 
La frase ofrece una actividad de descortesía manifiesta, en tanto que se acusa de mentir (es decir, de atentar contra una de las máximas conversacionales), lo cual, junto con el empleo del verbo "pretender" (que equivale a "simular", con las connotaciones de "engaño" que ambos tienen), y la concatenación de términos que siguen, irremediablemente lleva a evocar situaciones negativas que podrían resumirse en ideas como pobreza y retroceso. Esa polarización, junto con otra actividad descortés, como es una acusación -relacionada con la actividad económica-se agudiza más adelante, contraponiendo esta vez términos con connotaciones positivas ("trabajadores", "familias") a términos o situaciones marcadamente negativas (“codicia”, "falta de control”) y se refuerza en la frase final del párrafo, en la que se incide en la idea de ineficacia:

23. "Esta crisis no la han provocado los trabajadores ni las familias. La ha provocado la codicia y la falta de control sobre los mercados financieros amparada por la política y los políticos de la derecha [...] Quienes con sus ideas equivocadas nos condujeron a esta crisis no serán quienes nos saquen de ella”. (Carta de 2009 del PSOE, firmada por José Luis Rodríguez Zapatero y Juan Fernando López Aguilar)

Así, en comparación con 2004, en 2009 la imagen política de este partido se construye más apelando a "la diferencia" que se establece con "la derecha" que por rasgos definitorios acerca de la imagen propia, aunque estos también estén presentes. También en la carta de 2014 del PSOE hay una referencia expresa a "la derecha”, a la que además se atribuye un adjetivo (des)calificativo y cuyas medidas se rechazan, lo que en su conjunto supone una muestra de descortesía -en tanto que ataque directo- que se suma al hecho de recurrir a la polarización en la denominación empleada:

24. "En estos últimos años Europa ha estado gobernada por la derecha. Por una derecha insolidaria cuyas medidas han fracasado contra la crisis”. (Carta de 2014 del PSOE, firmada por Elena Valenciano)

Seguidamente se establece una dicotomía ellos-nosotros que se extiende a lo largo de varias frases, en las que se incluyen varios términos con connotaciones negativas:

25. "Nos han impuesto una política equivocada y unos sacrificios que no nos merecemos, que no han arreglado nada y que han hecho sufrir a mucha gente. Han perjudicado a España y a los españoles. Han puesto Europa en manos de los poderes financieros. Y mientras tanto han asfixiado la economía, han deteriorado la sanidad y a la educación pública [...]" (Carta de 2014 del PSOE, firmada por Elena Valenciano) 
A continuación, abandonando el "ellos”, continúa un ataque que, como tal, sigue siendo descortés, pero con un destinatario ambiguo, al que no se identifica o menciona explícitamente, sino al que el texto se refiere con términos como “algunos” y “otros”:

26. "La unidad de Europa trajo paz, progreso y libertad, y ayudó mucho al crecimiento de España. Pero hoy algunos sólo piensan en rescatar a los bancos con el dinero de los ciudadanos. Y otros quieren que el odio vuelva a Europa y volvamos a ver a los extranjeros como enemigos”. (Carta de 2014 del PSOE, firmada por Elena Valenciano)

Esta despersonalización, así como la dicotomía nosotros/ellos, se encuentra también en el texto enviado por Izquierda Unida en 2014:

27. "Sabemos que la mayoría estamos pagando injustamente la crisis y que algunos la están aprovechando para quitarnos derechos que, como pueblo, nos ha costado mucho conseguir”. (Carta de 2014 de Izquierda unida, sin firma expresa).

Poco después, la argumentación empleada por esta formación sigue en esta línea, en la que se lleva a cabo una actividad descortés, pero sin identificación clara de a quién va dirigida, en un nuevo ejemplo de descortesía despersonalizada, y en la que también se aprecia la dicotomía ellos/nosotros que a su vez da pie a la actividad de autoimagen, en la que se realza el valor ser diferente con respecto a aquello que se critica:

28. "Quienes tienen cuentas en Suiza, los que sí han vivido por encima de las posibilidades de la gente, pretenden salir de la crisis a costa de nuestros derechos, nuestros salarios y nuestras pensiones. Pero somos muchos y muchas ${ }^{15}$ quienes luchamos por un país diferente”. (Carta de 2014 de Izquierda unida, sin firma expresa $)^{16}$

15 Por primera vez en estas cartas -y más allá de lo que pueda suceder en las fórmulas rituales de saludo -, aparece el desdoblamiento de género ("muchos y muchas”).

16 Tanto en este ejemplo como en el número 30 (correspondiente a la carta de 2014 de Unidas Podemos cambiar Europa) se aprecian estructuras que apelan a la repetición para enfatizar su mensaje. En este sentido, cabe tener en cuenta la observación de Culpeper, Bousfield y Wichmann (2003, p. 1561) cuando señalan que [...] words, grammatical structures, intonational contours, or indeed any feature constituting a pragmatic strategy can be used repeatedly (usually in juxtaposition) to form a parallelism (a perceptually prominent pattern where some features are held constant and others may vary). [...]. The key point about the repetition (the parallelism) of impoliteness strategies relates to interpersonal effect: it increases the imposition upon the target and/or emphasizes the negative attitude of the speaker towards the target. In other words, it can boost impoliteness". 
También son estas las estrategias que aparecen en las cartas enviadas por Podemos en 2014 y 2019 (en este último año, como Unidas Podemos Cambiar Europa) desde el punto de vista de la descortesía. Incluso aunque se empleen términos con una fuerte carga peyorativa (como corruptos, sinvergüenzas o casta), no hay un destinatario claramente identificado, a la vez que se aprecia fácilmente la oposición ellos/nosotros:

29. “A diferencia de quienes nos gobiernan, tú sí sabes lo que pasa. Las políticas de recortes destruyen empleo, nos empobrecen y arruinan los proyectos de vida de jóvenes obligados a marcharse y de mayores que trabajaron duro toda su vida. Los corruptos que nos han traído hasta aquí no van a sacarnos de esta. Solo ejerciendo nuestra soberanía podremos cambiar nuestra vida y las de nuestras familias. [...] Vamos a defender en el Parlamento Europeo [...] un paquete de medidas anticorrupción que expulse a los sinvergüenzas de las instituciones y obligue a la casta que ha secuestrado nuestra democracia a rendir cuentas”. (Carta de 2014 de Podemos, firmada por Pablo Iglesias)

En el texto de 2019 también se encuentran varios ejemplos de descortesía. Si bien no en todos los casos se hace por igual modo explícito al destinatario de esos ataques, sí es claro que todos ellos están caracterizados de tal modo (élites económicas, unos pocos, millonarios, buitres financieros, extrema derecha, derecha extremada, ricos privilegiados ... ) que se constituyen en exogrupos con respecto a los emisores del texto. Después, como en otros casos, esas (des)calificaciones darán pie a una actividad de autoimagen, relacionada en este caso con la firmeza y la responsabilidad:

30. “[... [ nadie tiene que acostumbrarse a la desigualdad ni a la precariedad, mientras las élites económicas siguen enriqueciéndose. [...] No queremos una España vaciada, empobrecida y periférica, para el beneficio de unos pocos. Es verdad que la desigualdad no para de crecer, que aumenta el número de millonarios, y que los buitres financieros operan saltándose todas las reglas con la connivencia de unas instituciones que tienen a su servicio. [...] Pero no podemos permitir que la extrema derecha crezca alimentando ese miedo [...]. No queremos una Europa conflictiva ni excluyente [...]. Y esa es la Europa que quiere la extrema derecha y la derecha extremada: un club privado para ricos privilegiados y para el gran sector financiero". (Carta de 2019 de Unidas Podemos Cambiar Europa)

Cerramos esta sección con la carta del PSOE de 2019, en la que se busca la identificación con el lector empleando términos con connotaciones positivas y se 
confronta esa identificación con la actitud de otros, “ellos”, a los que se atribuyen acciones negativas (aunque, una vez más, sin mención expresa de quiénes constituyen ese exogrupo):

31. "Eliges entre una Europa más justa, verde y feminista, que fortalezca la unión entre europeos o una Europa que se desentienda de la gente, renuncie a sus principios colectivos y ceda ante el miedo”. (Carta de 2019 del PSOE, firmada por Josep Borrell y Pedro Sánchez)

En conjunto, el estudio de las actividades de descortesía en las cartas electorales que configuran nuestro corpus permite ver cómo la polarización aumenta con el paso de los años, cómo los ataques verbales se producen mayoritariamente -sobre todo a partir de 2009- sin un destinatario claramente identificado (aunque sí "[des] calificado"), y como la oposición nosotros/ellos (en donde "nosotros” puede emplearse tanto con un sentido inclusivo, en relación con lo estudiado en la sección anterior, como referido solo a la formación política, y en este caso como paso previo a una actividad de autoimagen) se revela como un mecanismo muy productivo cara a la imagen que se desea ofrecer a los (e)lectores.

\subsection{Actividades de autoimagen: de la imagen del candidato a la imagen del partido}

En las cartas electorales analizadas encontramos actividades de autoimagen personal, referidas exclusivamente al candidato que firma la carta y, de modo más habitual, actividades de autoimagen referidas al partido (del que el candidato es representante y, por tanto, también encarna esa imagen). Ofrecemos en primer lugar un análisis de actividades de autoimagen personales realizadas por Francisco Sosa (cabeza de lista de UPyD en 2014) y Dolors Montserrat (cabeza de lista del PP en 2019). Así, en la carta de UPyD, la actividad de autoimagen del candidato como una persona cortés aparece desde la primera línea del texto, así como una actividad de descortesía que si bien (al igual que en otros casos) no tiene un destinatario "claro", apunta tanto a sus contrincantes políticos como a los que, de modo indirecto, parece considerar sus "aliados”; los medios de comunicación:

32. "Me tomo la libertad de molestarle unos minutos porque es probable que mi nombre no se suene ya que represento a un partido joven y como tal excluido, por el juego de los viejos intereses, de la presencia constante de los medios de comunicación”. (Carta de 2014 de UPyD, firmada por Francisco Sosa) 
Las actividades de autoimagen que le caracterizan como una persona preparada, bien formada y comprometida (cualidades bien valoradas en el contexto sociocultural en el que se desarrolla la interacción) se acentúan en su presentación:

33. “Quiero significarle que en un momento como el actual [...] yo me presento ante usted como un jurista cualificado por mi condición de catedrático de Universidad y autor de muchos libros tanto jurídicos como históricos y de ensayo. Concibo pues mi dedicación a la política [...] como un compromiso noble [...]”. (Carta de 2014 de UPyD, firmada por Francisco Sosa)

Esas actividades de autoimagen continúan en el texto -vinculando ya al candidato al ámbito europeo- y, posteriormente, el firmante enumera las propuestas y los objetivos de su candidatura, lo que concluye en una frase que también revierte en su propia imagen de compromiso (elemento que, como se acaba de señalar, está bien valorado socioculturalmente). Además, esa imagen se hace extensible a su formación política:

34. "He sido diputado por esta formación política durante estos últimos cinco años [...]. Me siento orgulloso de haber llevado a Europa denuncias ciudadanas y obtenido pequeños logros que sin embargo han sido grandes para algunos conciudadanos. [...] Esta Europa que UPyD quiere ayudar a construir ha de estar firmemente comprometida con la defensa de los derechos y las libertades fundamentales que hoy han de ser bandera que nos distinga entre los ciudadanos del mundo”. (Carta de 2014 de UPyD, firmada por Francisco Sosa)

La llamada a la acción (petición de voto) se realiza igualmente con una actividad de imagen que potencia la humildad, en tanto que la fórmula empleada parece situarle en una posición inferior a la de su interlocutor:

35. "Con el fin de poder pelear por estos objetivos me atrevo a pedir su voto para la candidatura que encabezo de Unión Progreso y Democracia”. (Carta de 2014 de UPyD, firmada por Francisco Sosa)

En el caso de Dolors Montserrat, las actividades de autoimagen personal se sitúan prácticamente al final de la carta, pues los primeros párrafos son más institucionales (aunque en ellos también hay una actividad de autoimagen más ritualizada: “Tengo el honor de encabezar la candidatura [...] $)^{17}$. En la parte más personal, la candidata

17 Encontramos fórmulas similares en otras cartas de este mismo partido en diferentes elecciones. Así, en la carta de 2009 (firmada por J. Mayor Oreja) se indica "Para mí, es un motivo de orgullo el haber sido elegido de nuevo por el Partido Popular para encabezar la candidatura [...]"; en 2014, en la carta firmada por M. Arias Cañete se recoge "Por ello, llevar a Europa tu voz no solo supondría una gran responsabilidad, sino también, como español, un honor”. 
construye su imagen en relación con Europa del siguiente modo, en el que también se aprecia como un elemento destacado la constancia o tenacidad (características bien valoradas en el contexto sociocultural en el que estas cartas se generan):

36. “Soy de las primeras generaciones de Erasmus, así conocí el sueño europeo $^{18}$. Como ministra de Sanidad, Servicios Sociales e Igualdad he llevado la voz de España a las cumbres europeas [...] y soy una europeísta convencida. En Europa defenderé incansablemente los intereses de España y los españoles. En Europa defenderé la Europa que quieres”. (Carta de 2019 del PP, firmada por Dolors Montserrat)

Como puede apreciarse, estas actividades concluyen (aunque no de forma explícita) con la llamada a la acción, y tienen como intención presentar a la candidata como una persona con un profundo conocimiento sobre Europa, aunque en algún caso la referencia pueda resultar más anecdótica que profesional.

Por lo que se refiere a actividades de autoimagen de cada formación política, ofrecemos algunos ejemplos más que complementen lo expuesto en secciones previas:

37. "Hay que llevar al Parlamento Europeo a los europeístas: a quienes creen en Europa y a quienes quieren y pueden recuperar el protagonismo de España en Europa”. (Carta de 2004 del PSOE, firmada por José Luis Rodríguez Zapatero y por José Borrell)

En la frase anterior se establece una asimilación o identificación entre los emisores de la carta (el PSOE, aunque ahora se evite el nosotros y se plantee de modo más “distanciado") y quienes pueden llevar a cabo esa tarea. Se apela después al propio interés de los lectores (recurriendo de nuevo a la estrategia de acercamiento, y retomando el empleo de la primera persona de plural para ello):

38. "En Europa se toman muchas decisiones que afectan a nuestras vidas y a nuestros intereses. La acción conjunta de nuestro gobierno y de nuestros representantes en Europa es la forma más eficaz de defender los intereses de los españoles y de resolver los problemas que nos preocupan [...]”. (Carta de 2004 del PSOE, firmada por José Luis Rodríguez Zapatero y por José Borrell)

18 Como señala Lancheros (2020, p. 38), “en el caso de la imagen social, cada uno de los participantes construye un modelo mental propio de la imagen social de sí mismo y de los demás durante la interacción. [...] Las distintas representaciones mentales de la imagen social de una misma persona tendrán aspectos en común gracias a los conocimientos y experiencias compartidas de los interactuantes”. En este ejemplo, la apelación por parte de la candidata a los recuerdos o experiencias que los posibles (e)lectores puedan tener de sus propias experiencias Erasmus -que se entienden como positivas-, sin ser explícito, resulta claro. 
Así, la actividad de autoimagen del PSOE se construye en 2004 en torno a las ideas de impulso, fortaleza (como se apreciaba en el ejemplo 8) y eficacia. Este marco, en el que se relaciona la noción de "Europa" con la de "los intereses y los problemas de los españoles" refleja un ethos de solidaridad (Charaudeau, 2021, 165) y se relaciona también con una de las condiciones que, según este mismo autor, deben hacerse presentes para construir una imagen de credibilidad; la eficacia (Charaudeau, 2021; 123). De hecho, este término se encuentra en la "llamada a la acción" con la que termina la carta, en la cual sí se establece una distancia (o "diferenciación de grupos") entre los destinatarios y los emisores de la misiva, pues estos últimos formulan una petición a los primeros, a la vez que se resalta la imagen de España como entidad con características propias ${ }^{19}$, destacando así su imagen de autonomía (cfr. Bravo, 2003, 2004) ${ }^{20}$ en el marco internacional:

39. “Para que España vuelva con fuerza a Europa, [...] y para defender nuestros intereses con eficacia, le pedimos que el 13 de junio acuda a votar y que apoye a la candidatura del Partido Socialista” (Carta de $2004 \mathrm{del}$ PSOE, firmada por José Luis Rodríguez Zapatero y por José Borrell)

En este contexto, el hecho de pedir sitúa en cierta posición de inferioridad a quien pide; sin embargo, no se incluyen fórmulas ritualizadas que sí serían esperables en otros contextos (pedir por favor) ni se emplean verbos (como rogar) que pudieran aumentar la desigualdad entre quien pide y quien puede atender esa petición; la autoimagen que se ofrece, pues, busca un equilibrio (en tanto que una marcada “debilidad” no sería tampoco esperable en el discurso político) $)^{21}$.

Por su parte, la carta del Partido Popular de ese año, tras enumerar una serie de aspectos que buscan -también- crear un marco de eficacia ("El Partido Popular, durante todos estos años, ha defendido [...]”), orienta el texto a reforzar esa imagen, conjugándola con el ethos de competencia (entendido, siguiendo a Charaudeau, 2021, p. 128, como el hecho de "probar que tiene los medios, el poder y la experiencia necesarios para realizar concretamente sus objetivos y obtener resultados positivos"):

19 "Entre los hablantes españoles, la imagen de afiliación se relaciona, entre otros aspectos, con la confianza, mientras que "en la imagen de autonomía española encontramos contenidos como el del honor y el del orgullo" (Bravo, 2002, p. 145).

20 Se conceptualiza la imagen de autonomía como "aquella mediante la cual un integrante de un grupo adquiere un contorno propio dentro del mismo" (Bravo, 2004, p. 31).

21 "[...] el comportamiento cortés trata de alcanzar una situación de equilibrio entre la imagen social del destinatario y la del hablante, de forma que ambas se vean beneficiadas en algún grado, lo cual consiste en confirmar sus deseos de imagen en relación con los roles que están desempeñando [...]” (Hernández Flores, 2004: 100). 
40. "Esto es lo que han defendido nuestros parlamentarios y lo seguirán haciendo. [...] "Estamos comprometidos con la construcción de la Europa que todos queremos, más sólida y competitiva” (Carta de 2004 del PP, firmada por Mariano Rajoy y por Jaime Mayor Oreja)

Termina la carta recurriendo -al igual que en el texto del PSOE-a la idea de una España fuerte -con identidad propia, podría decirse-en Europa:

41. "Porque sabemos que te sientes tan comprometido como nosotros para lograr que España sea cada vez más fuerte en Europa”. (Carta de 2004 del PP, firmada por Mariano Rajoy y por Jaime Mayor Oreja)

Así, las actividades de autoimagen de este partido se estructuran desde el marco de fortaleza, dinamismo y búsqueda de los intereses nacionales con respecto a otros países, pero apelando a un compromiso común, lo que supone buscar un grado de identificación elevado entre emisores y receptores. La carta termina igualmente llamando a la acción desde una premisa de reciprocidad:

42. "Si quieres asegurarte de que estos sean los asuntos que se defiendan en Europa, vota al Partido Popular” (Carta de 2004 del PP, firmada por Mariano Rajoy y por Jaime Mayor Oreja)

En las cartas de 2009 de esta misma formación, su autoimagen (en este caso, en la carta de M. Rajoy) se sigue construyendo en torno a la idea de eficacia:

43. "Y es cierto que hay soluciones. El PP lo demostró en su día creando más empleo y reduciendo más el paro que ningún otro Gobierno en la historia de nuestra democracia”. (Cartas de 2009 del PP, firmada por Mariano Rajoy y por Jaime Mayor Oreja)

Desde esa referencia de cercanía -contexto nacional-, se extrapola la acción al ámbito europeo (lo cual es también una práctica habitual en las cartas de otras formaciones políticas), para profundizar en una imagen de fortaleza:

44. "Pero es muy importante, es decisivo, para que esas soluciones funcionen, que los intereses de España se defiendan adecuadamente en Europa [...] Defender nuestros intereses y contribuir a la construcción europea son objetivos compatibles”. (Cartas de 2009 del PP, firmadas por Mariano Rajoy y por Jaime Mayor Oreja)

En la carta de Mayor Oreja, por su parte, a partir de una actividad de descortesía en la que de nuevo se emplea el nosotros y en la que una vez más se recurre al ámbito español (aunque se trate de unas elecciones europeas) se origina una actividad de autoimagen en la que se establece -o se desea establecer-un "terreno común” con 
los lectores, basado esta vez en la idea de firmeza. Las actividades de autoimagen continúan en esa carta a partir de las ideas de seguridad y confianza:

45. "El 7 de Junio podemos decirle al Gobierno que no estamos dispuestos a seguir instalados en la crisis económica y social que vive España [...] Podemos devolverle a la sociedad la confianza en el futuro de la que hoy carece" (Cartas de 2009 del PP, firmadas por Mariano Rajoy y por Jaime Mayor Oreja)

Al final del texto, se apela a los lectores desde una postura de humildad (como es solicitar la colaboración de otros), a la que se suman el agradecimiento y nuevamente la confianza, lo que constituyen también actividades de autoimagen:

46. "Para lograrlo, necesitamos la colaboración de todos. La de quienes nos han votado otras veces y la de aquellos que no lo han hecho hasta ahora, pero entienden que es necesario cambiar de rumbo". [...] “Contamos con su compromiso y su apoyo, por lo que le doy las gracias de antemano, en la certeza de que nuestro triunfo será en beneficio de todos los españoles”. (Cartas de 2009 del PP, firmadas por Mariano Rajoy y por Jaime Mayor Oreja)

En esta última frase se opta por mantener al comienzo la diferenciación entre emisores y receptores ("Contamos con su compromiso y su apoyo..."), para virar después hacia un "nuestro" ("nuestro triunfo") que, si bien en la práctica se refiere a los emisores en tanto que políticos, repercuta en el conjunto de la comunidad (y no solo en ese "nosotros" como emisores). Ello supone un desplazamiento “amplificador" del sentido de ese nuestro y, en este sentido, una diferencia respecto de la polarización nosotros/ellos presente en otros ejemplos.

Por su parte, la carta del PSOE de 2009 (a partir de la polarización que se ha expuesto en el ejemplo 21, que aquí recuperamos), construye su autoimagen sobre la idea de progreso, al erigirse en detractores de una medida que, según el texto, supondría un acusado retroceso en los derechos sociales.

21. "Le pondremos un ejemplo: hace unos meses, la derecha pretendió implantar en toda Europa la jornada laboral de 65 horas semanales. Los socialistas españoles nos enfrentamos a ello y conseguimos frenarlo. Si la derecha hubiera tenido la mayoría, hoy los derechos sociales en Europa habrían retrocedido varias décadas" (Carta de 2009 del PSOE, firmada por José Luis Rodríguez Zapatero y Juan Fernando López Aguilar).

Esta idea se ve reforzada, además, por la frase siguiente:

47. "Estamos luchando para superar la crisis económica y a la vez apoyar más a quienes más la sufren: los trabajadores, las familias, las empresas que tienen dificultades para salir adelante”. (Carta de 2009 del PSOE, firmada por José Luis Rodríguez Zapatero y Juan Fernando López Aguilar) 
Así, las estrategias de autoimagen de esta formación se construyen a partir de ideas como progreso, decisión, solidaridad y empatía, y por contraposición a las del exogrupo, al que se asocia con retroceso, codicia e ineficacia.

En 2014, en la carta del PP de M. Rajoy se encuentran estrategias de autoimagen basadas en las ideas de justicia y dinamismo, así como, de nuevo, humildad y eficacia:

48. "En estos 2 años hemos adoptado medidas difíciles pero siempre tratando de ser justos y equitativos. Y hoy puedo afirmar que España va en la buena dirección. Queda mucho, lo sé, pero el crecimiento económico y la creación de empleo neto que hoy son una realidad, serán la base [...]. (Cartas de 2014 del PP, firmadas por Mariano Rajoy y Miguel Arias Cañete)

La carta de M. Arias incluye otra actividad de autoimagen que presenta al remitente como alguien que pone sus cualidades al servicio de los ciudadanos, y esto repercute también beneficiosamente en su propia imagen como alguien tenaz:

49. “[...] compartimos con nuestros socios un espacio de libertad, prosperidad y progreso. Pero nadie regala nada. Mi experiencia política a lo largo de estos años defendiendo los intereses de mis conciudadanos [...] me ha enseñado que solo con esfuerzo, dedicación y constancia, uno puede lograr los objetivos que se proponga”. (Cartas de 2014 del PP, firmadas por Mariano Rajoy y Miguel Arias Cañete)

Por su parte, la carta de 2014 del PSOE, firmada por Elena Valenciano, recurre al empleo de "nosotros" para la actividad de autoimagen, con referencias positivas que apelan al valor de humanidad ${ }^{22}$ :

50. "Queremos un reconocimiento del europeísmo. Queremos recuperar la Europa con rostro humano a la que siempre hemos deseado pertenecer. Los socialistas queremos ganar estas elecciones para la gente que más ayuda necesita [...]”. (Carta de 2014 del PSOE, firmada por Elena Valenciano)

La polarización ellos/nosotros, derecha/izquierda (es la primera vez que este último vocablo aparece explícito en estas cartas), junto a conceptos a los que se atribuyen connotaciones negativas y positivas respectivamente (poderes financieros/ciudadanos), y que también se contraponen, se recupera una vez más para la actividad de autoimagen final:

22 "El ethos de «humanidad» también es un imaginario importante para la imagen del político. «Ser humano» se mide por la capacidad de dar muestras de sentimientos, de compasión para con los que sufren, [...]”. (Charaudeau, 2021, p. 151). 
51. "Solo hay dos mayorías posibles en Europa: o gobierna la derecha y los poderes financieros; o gobierna la izquierda para devolver Europa a los ciudadanos”. (Carta de 2014 del PSOE, firmada por Elena Valenciano)

En cuanto a Podemos -y adicionalmente a lo señalado en la sección anterior-, cabe destacar que en su carta de 2014 hay varias actividades de autoimagen (basadas fundamentalmente en las connotaciones positivas de los términos empleados: iniciativa ciudadana, sentido común, cambios sencillos pero profundos ... ), referidas tanto a la formación en sí, como a los candidatos que presentó a esas elecciones:

52. "Podemos es una nueva iniciativa ciudadana que propone ideas de sentido común: democracia y soberanía, trabajo y dignidad. Proponemos cambios sencillos pero profundos, que ya defiende una mayoría social [...] Nos presentamos a las elecciones europeas con personas preparadas y decentes [...]. Proponemos un cambio de rumbo, una Europa para la gente”. (Carta de 2014 de Podemos, firmada por Pablo Iglesias)

La actividad de autoimagen se recupera en la pregunta con la que se cierra la carta, pregunta que puede relacionarse con la cortesía -en tanto que se interesa por el destinatario-, pero también con la imagen que la formación se atribuye, el ser ilusionante (“¿Cuándo fue la última vez que votaste con ilusión?”) y la petición de voto para esa formación.

\section{Conclusiones}

Las cartas electorales constituyen, como hemos podido comprobar, un terreno abonado para las actividades de cortesía, descortesía y autoimagen por parte de los actores políticos. Sin embargo, y con independencia de la ideología subyacente en las cartas, estas actividades se presentan, en nuestro corpus, con algunas características determinadas:

- Las actividades de cortesía se dirigen siempre hacia los (e)lectores, a quienes se desea halagar con un fin persuasivo (obtener el voto).

- Dentro de esas actividades de cortesía resalta el empleo de la primera persona de plural (nosotros) como forma de acortar distancias con los (e)lectores y constituir de ese modo un único grupo en el que se comparten -supuestamente- puntos de vista, preocupaciones, intereses y objetivos.

- En otras ocasiones, sin embargo, el empleo de la primera persona de plural se limita a un uso más restrictivo, circunscrito al partido político que actúa como 
emisor de la carta. Incluso en esos casos, se busca la complicidad con el lector, con independencia de la fórmula (tú/usted) empleada, basándose en los puntos de vista -de nuevo supuestamente- compartidos, lo que se realiza también como estrategia de persuasión.

- Las actividades de descortesía se dirigen, fundamentalmente, a los oponentes políticos (ellos), si bien en algunas ocasiones también son objeto de esas actividades descorteses otros actores sociales. En esas actividades descorteses rara vez se menciona expresamente el nombre del (o de los) partido(s) político(s) adversario(s) o actores sociales a los que se critica, de ahí que hablemos de una descortesía matizada o despersonalizada, lo cual relacionamos con la voluntad, por parte del emisor, de salvaguardar su propia imagen mediante ataques verbales más vagos -y, en cierto sentido, eufemísticos-que los que se producirían si se identificara abierta y explícitamente al (o a los) destinatario(s) de esos ataques, incluso aunque estos posean una fuerte carga peyorativa en su formulación.

- La autoimagen de los candidatos -y, por extensión, de los partidos-se construye tanto por las actividades de cortesía y descortesía empleadas, como por el empleo de términos con los que crean el marco con el que desean presentarse ante los ciudadanos. En este sentido, vocablos como eficacia, solidaridad, confianza, responsabilidad, progreso... resultan especialmente rentables para la imagen mostrada en estos textos, y en numerosas ocasiones aparecen en las cartas de candidatos con orientaciones ideológicas dispares.

Confiamos en que este trabajo pueda abrir camino a otros investigadores que deseen realizar análisis similares o con los que establecer comparaciones, bien referidas a otros tipos de comicios, bien elaboradas desde la perspectiva de otras variedades del español y, por ende, de otros contextos socioculturales.

\section{Referencias}

Abejón, P., y Mayoral, J. (2017). Persuasión a través de Facebook de los candidatos en las elecciones generales de 2016 en España. El Profesional de la Información, 26(5), 928-936. Abejón, P., Sastre, A., y Linares, V. (2012). Facebook y Twitter en campañas electorales en España. Anuario Electrónico de Estudios en Comunicación Social, 5(1), 130-159.

Alcántara-Plá, M., y Ruiz, A. (2018). Not for Twitter: Migration as a silenced topic in the 2015 Spanish general election. En M. Schröter, y C. Taylor (Eds.), Exploring silence and absence in discourse. Postdisciplinary studies in discourse (pp. 25-64). Cham: Palgrave Macmillan. Anaya Revuelta, I. (2018). ¿Para qué sirven las cartas electorales? En M. Díaz Ferro, et al. (Eds. Lits.), Actas do XIII congreso internacional de lingüística xeral (pp. 71-78). Vigo: Universidad. 
Ballesteros, C. A., y Gómez, S. (2020). Batalla de frames en la campaña electoral de abril de 2019. Engagement y promoción de mensajes de los partidos políticos en Facebook. El Profesional de la Información, 29(6), 1-17.

Bernal, M. (2007). Categorización sociopragmática de la cortesía y de la descortesía. Un estudio de la conversación coloquial española. Estocolmo: Universidad.

Bolívar, A., y Escudero, A. (2021). La descortesía de Donald Trump hacia los migrantes mexicanos y la respuesta de La Jornada en sus editoriales: La descortesía como práctica política. Pragmática Sociocultural, 9(1), 1-25.

Bou, P., y Garcés, P. (2003). Teaching linguistic politeness: A methodological approach. International Review of Applied Linguistics in Language Teaching, 41, 1-22.

Bravo, D. (2002). Actos asertivos y cortesía: Imagen del rol en el discurso de académicos argentinos. En M.a.E. Placencia, y D. Bravo (Eds.), Actos de habla y cortesía en español (pp. 141-174). Munich: Lincom.

Bravo, D. (2003). Actividades de cortesía, imagen social y contextos socioculturales: Una introducción. En D. Bravo (Ed.), La perspectiva no etnocentrista de la cortesía: identidad sociocultural de las comunidades hispanohablantes. Actas del Primer Coloquio del Programa EDICE (pp. 98-108). Estocolmo: Programa Edice. Retrieved from http://www. edice.org.

Bravo, D. (2004). Tensión entre universalidad y relatividad en las teorías de la cortesía. En D. Bravo, y A. Briz (Eds.), Pragmática sociocultural: estudios sobre el discurso de cortesía en español (pp. 15-38). Barcelona: Ariel.

Bravo, D. (2005). Categorías, tipologías y aplicaciones. Hacia una redefinición de la cortesía comunicativa. En D. Bravo (Ed.), Estudios de la (des)cortesía en español. Categorías conceptuales y aplicaciones a corpora orales y escritos (pp. 21-52). Buenos Aires: Dunken, Edice.

Bravo, D. (2020). Pragmática sociocultural para el análisis de los aspectos sociales del discurso. En M. V. Escandell, J. Amenós, y A. Ahern (Eds.), Pragmática (pp. 481-497). Barcelona: Akal.

Briz, A. (2004). Cortesía verbal codificada y cortesía verbal interpretada en la conversación. En D. Bravo, y A. Briz (Eds.), Pragmática sociocultural: estudios sobre el discurso de cortesía en español (pp. 67-94). Barcelona: Ariel.

Charaudeau, P. (2004). Tiers où es-tu? En P. Charaudeau (Ed.), La voix cachée du Tiers. Des nondits du discours (pp. 19-41). París: L'Harmattan.

Charaudeau, P. (2021). El discurso político. Las máscaras del poder [2005]. Buenos Aires: Prometeo.

Culpeper, J., Bousfield, D., y Wichmann, A. (2003). Impoliteness revisited: With special reference to dynamic and prosodic aspects. Journal of Pragmatics, 35, 1545-1579.

Cussó, R., y Gobin, C. (2008). Du discours politique au discours expert. Le changement politique mis hors debat? Mots. Les langages du Politique, 88, 5-11.

De Santiago, J. (2020). La comunicación persuasiva: Discurso político y discurso publicitario. En M.a.V. Escandell, J. Amenós, y A. Ahern (Eds.), Pragmática (pp. 427-445). Barcelona: Akal.

Garcés, P. (1995). Revisión crítica de algunos de los postulados de la teoría de la cortesía lingüística propugnada por Brown y Levinson. Quaderns de Filologia: Estudis Linguistics, 1, 43-61.

Goffman, E. (1967). Interaction ritual: Essays on face-to-face behaviour. Nueva York: Doubleday Anchor Books.

Gómez Sánchez, M. ${ }^{a}$ E. (2006). Cortesía y eufemismo. Los sustitutos eufemísticos en la prensa y la defensa de la propia imagen. En J. L. Blas Arroyo, M. Casanova Ávalos, y M. Velando Casanova 
(Eds.), Discurso y sociedad: contribuciones al estudio de la lengua en contexto social (pp. 625-636). Castellón: Universitat Jaume I.

Gómez Sánchez, M. ${ }^{a}$ E. (2008). Actividades de imagen en la entrevista política: Algunos ejemplos de estrategias discursivas para la configuración de la imagen pública. Anuario de Estudios Filológicos, XXXI, 21-35.

Hernández Flores, N. (2004). La cortesía como la búsqueda del equilibrio de la imagen social. En D. Bravo, y A. Briz (Eds.), Pragmática sociocultural: estudios sobre el discurso de cortesía en español (pp. 95-108). Barcelona: Ariel.

Hernández Flores, N. (2006). Actividades de autoimagen, cortesía y descortesía: Tipos de actividades de imagen en un debate televisivo. En J. L. Blas Arroyo, M. Casanova Ávalos, y M. Velando Casanova (Eds.), Discurso y sociedad: contribuciones al estudio de la lengua en contexto social (pp. 637-648). Castellón: Universitat Jaume I.

Hernández Flores, N. (2013). Actividad de imagen: Caracterización y tipología en la interacción comunicativa. Pragmática Sociocultural, 1(2), 175-198.

Hernández Flores, N., y Gómez Sánchez, M. ${ }^{a}$ E. (2014). Actividades de imagen en la comunicación mediática de medidas políticas contra la crisis: El copago sanitario. Revista de Filología, 32, 125-143.

Igartua, J. J., Muñoz, C., y Cheng, L. (2005). La inmigración en la prensa española. Aportaciones empíricas y metodológicas desde la teoría del encuadre noticioso. Migraciones, 17, 143-181.

Kaul de Marlangeon, S. (2017). Tipos de descortesía verbal y emociones en contextos de cultura hispanohablante. Pragmática Sociocultural, 7(1), 1-23.

Kaul de Marlangeon, S., y Cordisco, A. (2014). La descortesía verbal en el contexto políticoideológico de las redes sociales. Revista de Filología, 32, 145-162.

Kienpointner, M. (1997). Varieties of rudeness. Types and functions of impolite utterances. Functions of Language, 4(2), 251-287.

Koch, P., y Oesterreicher, W. (1990). Gesprochene sprache in der Romania: Französisch, Italienisch, Spanisch. Tubinga: Niemeyer.

Lakoff, R. (1973). Language in context. Language, 48(4), 907-927.

Lakoff, R. (1989). The limits of politeness: Therapeutic and courtroom discourse. Multilingua, 8 , 101-129.

Lancheros Redondo, H. F. (2020). Nuevas reflexiones en torno a imagen social, actividad de imagen y (des)cortesía. In M. González-Sanz, C. Fuentes y E. Brenes (Eds.), (Des)cortesía, actividades de imagen e identidad (pp. 37-47). Sevilla: Universidad.

López Meri, A., Marcos García, S., y Casero Ripollés, A. (2020). Estrategias comunicativas en Facebook: Personalización y construcción de comunidad en las elecciones de 2016 en España. Doxa Comunicación, 30, 229-248.

Marcos García, S., Alonso Muñoz, L., y López Meri, A. (2021). Campañas electorales y Twitter. La difusión de contenidos mediáticos en el entorno digital. Cuadernos. info, 48, 27-47.

Narvaja de Arnoux, E. (2021). Los discursos de la política. En Ó. Loureda, y A. Schrott (Eds.), Manual de lingüística del hablar (pp. 733-748). Berlín: De Gruyter.

Oesterreicher, W. (1996). Lo hablado en lo escrito: Reflexiones metodológicas y aproximación a una tipología. En T. Kotschi, W. Oesterreicher, y K. Zimmermann (Eds.), El español hablado y la cultura oral en España e Hispanoamérica (pp. 317-340). Madrid, Frankfurt: Iberoamericana, Vervuert.

Pérez Vicente, N. (2016). Esto no hay quien se lo coma: Análisis contrastivo español-italiano de la descortesía verbal en televisión. Orillas, 5, 1-14. 
Pons, L. (2021). El hablar y lo escrito. En Ó. Loureda, y A. Schrott (Eds.), Manual de lingüística del hablar (pp. 287-306). Berlín: De Gruyter.

Ridao, S. (2009). Y es que usted cambia de criterio cada cuarto de hora: Las estrategias de (des) cortesía en los debates electorales españoles de 2008. Linguistica en la Red, 7, 1-19.

Sampietro, A., y Valera, L. (2015). Emotional politics on Facebook. An exploratory study of Podemos' discourse during the European election campaign 2014. Ricerca. Revista de Pensament y Anàlisi, 17, 61-83.

Van Dijk, T. (1999). Ideología. Una aproximación multidisciplinaria. Barcelona: Gedisa.

Van Dijk, T. (2012). Discurso y contexto. Un enfoque sociocognitivo. Barcelona: Gedisa.

Van Dijk, T., Ting-Toomey, S., Smitherman, G. y Toutman, D. (2000): Discurso, filiación étnica, cultura y racismo. En T. Van Dijk (Ed.), El discurso como interacción social. Estudios del discurso: introducción multidisciplinaria. (Vol. 2, pp. 213-216). Barcelona: Gedisa.

Verón, E. (1987). La palabra adversativa. Observaciones sobre la enunciación política. En AAVV (Ed.), El discurso político. Lenguajes y acontecimientos (pp. 11-26). Buenos Aires: Hachette.

Zugasti, R., y García, C. (2018). Los temas de los líderes políticos en Twitter. Análisis de las dos campañas electorales de 2015. Icono 14, 16(1), 136-159. 